\title{
Adding Psychological Factor in the Model of Electricity Consumption in Office Building
}

\author{
Meredita Susanty \\ Department of Computer Science, University Pertamina, Indonesia
}

\begin{tabular}{l} 
Article Info \\
\hline Article history: \\
Received Feb 14, 2018 \\
Revised Jul 22, 2018 \\
Accepted Aug 6, 2018 \\
\hline
\end{tabular}

Keyword:

Agent-based modelling and simulation

Behaviour

Energy Consumption

\begin{abstract}
Researches indicate that energy behaviour is the key to energy conservation and suggest that comparative feedback on energy usage can generate savings in residential and organizational settings. In implementing comparative feedback in workplace, there are two different ways to disaggregate collective energy consumption and apportion it to building users; individual or group level. This research uses agent-based modelling and simulation to examine the impact of applying different approaches of energy data apportionment to change staff behaviour toward energy consumption reduction. A simulation model of energy consumption in workplace as a base model is a re-implementation and simplification from former research. Several psychological factors and decision-making mechanism are then being added as an extension. The model divides staffs into four energy awareness stereotypes based on motivation level. Sensitivity analysis suggests that motivation is an important factor in changing user's behaviour and the experiment results indicates greater potential for energy saving when energy usage is apportioned to group level. The significant difference of energy consumption level makes user with low and medium motivation should become the target of energy reduction campaign.
\end{abstract}

Copyright (c) 2018 Institute of Advanced Engineering and Science. All rights reserved.

Corresponding Author:

Meredita Susanty,

Department of Computer Science,

University Pertamina,

J1 Teuku Nyak Arief Kebayoran Lama Jakarta Selatan 12220, Indonesia.

Email: meredita.susanty@universitaspertamina.ac.id

\section{INTRODUCTION}

Besides building automation system which is installed to integrate, monitor and control electrical and mechanical devices, motivating people to become better climate stewards might be the next big win for the planet. Researches indicate that energy behaviour is key to energy conservation and suggest that comparative feedback on energy usage can generate savings in residential and organizational settings [1], [2]. An agent-based model which integrates four important elements; organizational energy management policies/regulations, energy management technologies, electric appliances and equipment, and human behaviour was developed by Zhang [3] to comprehensively understand the complex organisational issue of office energy consumption. The researchers acknowledged some limitations in their model. Firstly, an electricity user agent's stereotype in the model is fixed. However, they noted that in the reality the switch of stereotypes might happen, although the probability for such occurrence is low. The second, assumption that enhancing interactions about energy issues between staff can increase staff's energy saving awareness which is correct in a situation where electricity users have to bear the cost of electricity. However, they have not found any sound evidence to support this assumption as staff do not have to bear the cost of electricity, which may result in the assumption in question.

Behavioural science experiment showed that encouraging people to save power because it is environmentally friendly or economical usually do not change their long-term habits [1]. Researcher tried a 
cleverer tactic from social psychology which had the probability to make a lasting impact called normative comparison. It gives those same people clear, personalized insights into their energy use, then add context by comparing them to each other. Scientist believe if this approach is applied to home energy use it is an astonishingly reliable way to motivate people to make smarter decisions [1], [2], [4].

Bedwell [5] in his literature review indicates greatest potential for energy saving by changing user behavior. It is said that disaggregation of energy data and apportionment is valuable to leverage data for behavioural change and is concluded that setting clear specific goal within and coherent with company strategy is likely to be effective and more so if specific feedback on these goals are provided.

Model socio-technical system of energy consumption in workplace is used in this paper to analyse the impact of implementing different strategies to promote energy saving awareness and motivate staff to change their behaviour. This model aims to find the impact of adding psychological factors for electricity consumption in office building and to understand the impact of applying different approaches of energy data apportionment to change staff behaviour toward energy consumption reduction.

The paper is organized as follows. In Section 2, present the specification and design of the model. In Section 3, we describe the experimental design, execution and validation. In Section 4, the simulation results of the model are presented. Finally, some conclusions are presented in Section 5.

\section{MODEL DEVELOPMENT}

\subsection{Conceptualization}

The conceptual model was developed using a framework described in Robinson [6]. It is started with an understanding of the problem situation. A set of modelling objectives are then determined. These objectives then drive the derivation of the conceptual model, first by defining the inputs and outputs, and then by defining the content of the model itself. Table 1 shows Model Specification.

Table 1. Model Specification

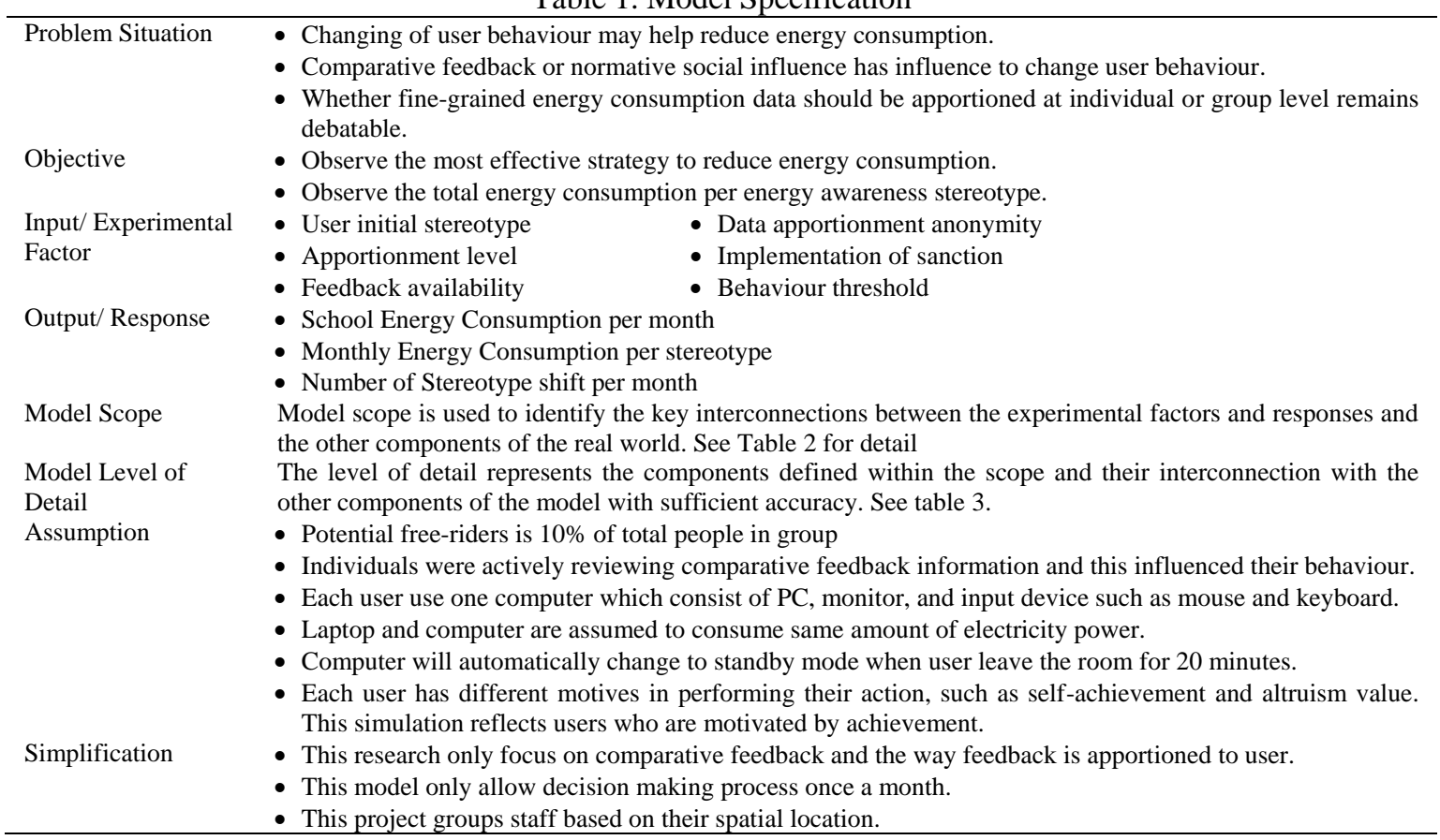

\subsection{Design}

This model is a simplification of a former model [3] which consists of 5 object classes; User, Office, Light, Computer and Main. A new algorithm, which implement psychological factors, for decision making was added into the user agents and is executed at the end of the month. Table 2 shows model of scope. Table 3 shows model level of detail. 
Table 2. Model of Scope

\begin{tabular}{|c|c|c|c|}
\hline Element & Detail & Decision & Justification \\
\hline \multirow{3}{*}{ Actor } & UG + MSc Students & Exclude & Do not have control over their work environment \\
\hline & $\begin{array}{l}\text { Heating, Ventilating, Air } \\
\text { Conditioning (HVAC) System }\end{array}$ & Exclude & $\begin{array}{l}\text { Only need one major energy consuer to test the theory; } \\
\text { decided to go for electricity }\end{array}$ \\
\hline & Lighting & Include & Interacts with users on a daily basis; controlled by user \\
\hline \multirow{2}{*}{ Appliances } & $\begin{array}{l}\text { Continuously running } \\
\text { appliances }\end{array}$ & Exclude & $\begin{array}{l}\text { Constant consumption of electricity; not controllable by } \\
\text { individuals }\end{array}$ \\
\hline & Personal appliances & Exclude & No way to measure consumption \\
\hline \multirow[t]{2}{*}{ Weather } & Temperature & Exclude & Not necessary for proof-of-principle \\
\hline & Natural Light Level & Exclude & Not necessary for proof-of-principle \\
\hline Room & Corridor & Include & Commonly used when users move around \\
\hline \multirow[t]{6}{*}{$\begin{array}{l}\text { Psychological } \\
\text { Factors }\end{array}$} & Comparative Feedback & Include & $\begin{array}{l}\text { Effective strategy to reduce energy consumption in } \\
\text { residential building }\end{array}$ \\
\hline & Informative Feedback & Include & $\begin{array}{l}\text { Effective strategy to remove barriers in performing } \\
\text { specific behavior }\end{array}$ \\
\hline & Apportionment Level & Include & $\begin{array}{l}\text { Effective strategy to reduce energy consumption in office } \\
\text { building }\end{array}$ \\
\hline & Freeriding & Include & Behaviour that differentiate two apportionment strategy \\
\hline & Sanction & Include & Factor to encounter freeriding behavior \\
\hline & Anonymity & Include & \\
\hline
\end{tabular}

Table 3. Model Level of Detail

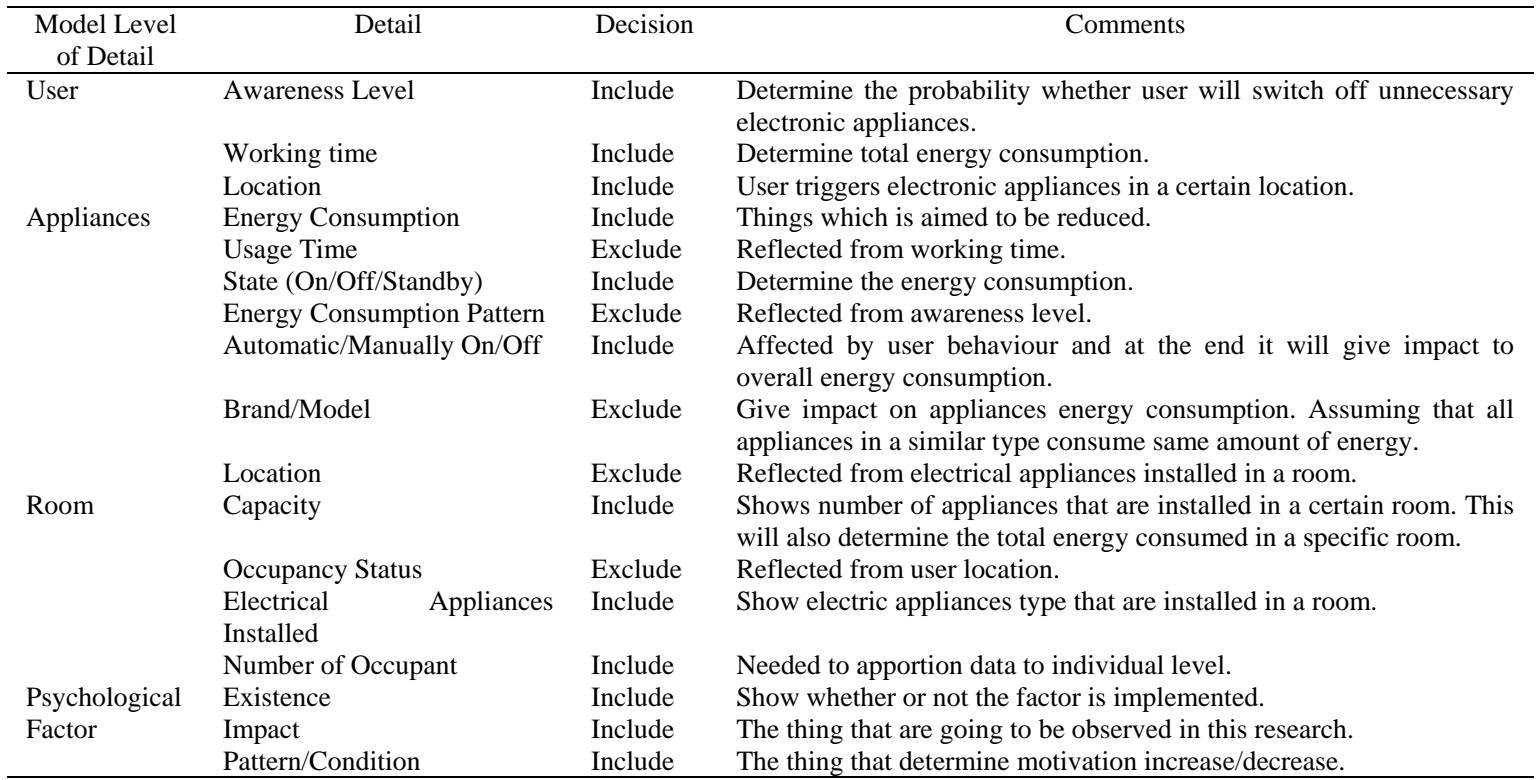

\subsubsection{Behaviour of Electricity User Agents}

User, an active agent who triggers energy consumption in workplace, starts to consume electricity when they arrive in an office building. To find their own office, user walk from one room to another. The communal room where user passes to reach their own office is generalised as corridor. Besides that, user also uses other rooms such as toilet, pantry, lab, meeting room. When user leaves office building, their energy consumption is expected to be zero. However, if they do not switch off their electronic appliances, their electricity consumption is still counted. These processes are represented in a statechart in the simulation model. The state in statechart shows location in the office building while state inside it shows user's action when they occupy the office. Total electricity which is consumed by each user is calculated using the following formula: 


$$
\epsilon=\frac{\sum l}{o}+c
$$

$\epsilon$ : own energy, $\sum l$ : energy of all lights in a room that user is occupied $o$ : number of occupant, $c$ : energy of computer

The nature and data about user behaviour that is used in this project was gained from former research [3], categorized user based on their working time [3] and energy saving awareness [3] used of user's movement from one location to the other as their state. While [3] implements three different electricity management strategy - automated, mixed and manual, this model only implemented the mixed strategy when user is expected to switch off the electronic appliances manually when they leave a room but in case they do not switch it off, it will be automatically switch off or standby in a certain time after they leave that room.

New algorithm is based on several psychological factors, namely normative social influence, behaviour-specific ability and additional factors for group apportionment because of the potential free riding act, anonymity in data apportionment and the implementation of sanction. Those factors will change user's motivation. Since energy saving awareness stereotype determine user's motivation level, in reverse changes in user motivation level will also change their stereotype. The flowchart in Figure 2 represents the logic of the algorithm which links the logic to its rationale in Table 3 based on [5].
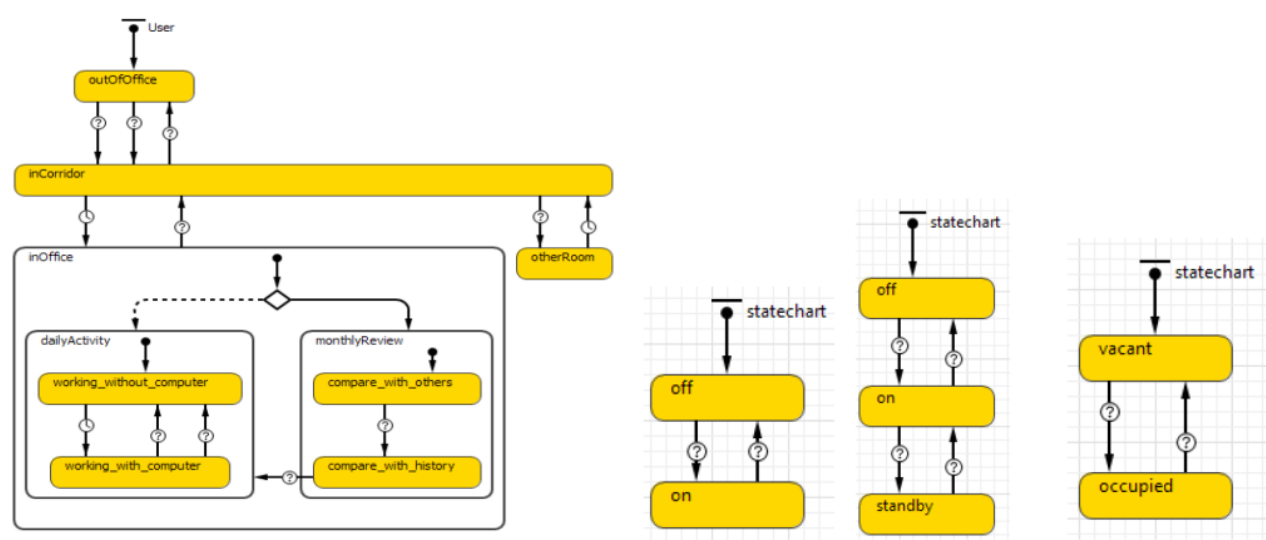

Figure 1. (a) User Agent (b) Light Agent (c) Computer Agent (d) Office Agent State Chart

The algorithm is triggered at the end of the month, a summary of user's total electricity consumption is presented together with information about the majority of other users' consumption. Based on this information, people will make comparison with other people performance and comparison with their performance in the previous month. Data apportionment to individual and group leads to different formula to calculate total energy consumption. In a room occupied by more than one user, if data is apportioned to individual level the total of light energy consumption is divided by the number of room occupant. When data is apportioned to group level, implementation of sanction will reduce the number of free rider by increasing their motivation and specific evidence of one's consumption (not anonymous) will put pressure on themselves to perform better in the future because of lateral control which will increase their motivation.

Furthermore, there is another factor namely behaviour specific ability that might have impact to motivation but is not depicted in Figure 1(a). Providing practical tips on how to perform better in conserving energy in office building is increasing people motivation or in a situation when people's motivation is decreasing, the value of motivation decrease is lower than if this practical information is not available. The availability of practical information is represented as a variable named feedback in the model as shown in Figure 2.

\subsubsection{Behaviour of Light Agents}

Light, a passive agent and is installed in each room in the building, has 2 states, on (consume 60W) and off (0W) [3], shown in Figure 1(b). Initially, lights in a room is off. User presence in a room triggers automated light sensor which will switch the light on. Light will be off either if user switch it off or if the sensor does not detect any user presence for 20 minutes.

\subsubsection{Behaviour of Computer Agents}

Computer, a passive agent and only available in user's office room, has three states, off ( $0 \mathrm{~W})$, on $(400 \mathrm{~W})$ and standby $(25 \mathrm{~W})$, as shown in Figure 1(c). It changes from on state to off state and vice versa 
because of user's action. When user is not in the room for a certain period and does not switch the computer off, it will automatically change its state to standby then back to state on when it detects users' action.

\subsubsection{Behaviour of Office Agents}

Office agent is a passive agent that represents a certain location in an office building. Computers and lights are installed in an office, while corridor and other room only have lights. User occupies an office during the day. It has two states, vacant and occupied, based on user presence as shown in Figure 1(d). When users occupy a room, their presence triggers the light on and he/she might switch the computer on. Both actions start energy consumption in a room. Conversely, when user leaves a room energy consumption will be zero if they switch off all appliances before leaving. Otherwise, after a certain time, the light will automatically switch off and computer will keep consuming $25 \mathrm{~W}$ of energy because it enters standby state. The new algorithm rationale as shown in Table 4. Since apportionment to group level categorised people based on their spatial location, the formula below is used to calculate group consumption:

$$
\sum e_{c}=\sum l+\sum c
$$

$\sum e_{c}$ : Total Energy Consumption, $\sum l:$ energy of all lights installed in the room, $\sum c$ : energy of computer installed in the room
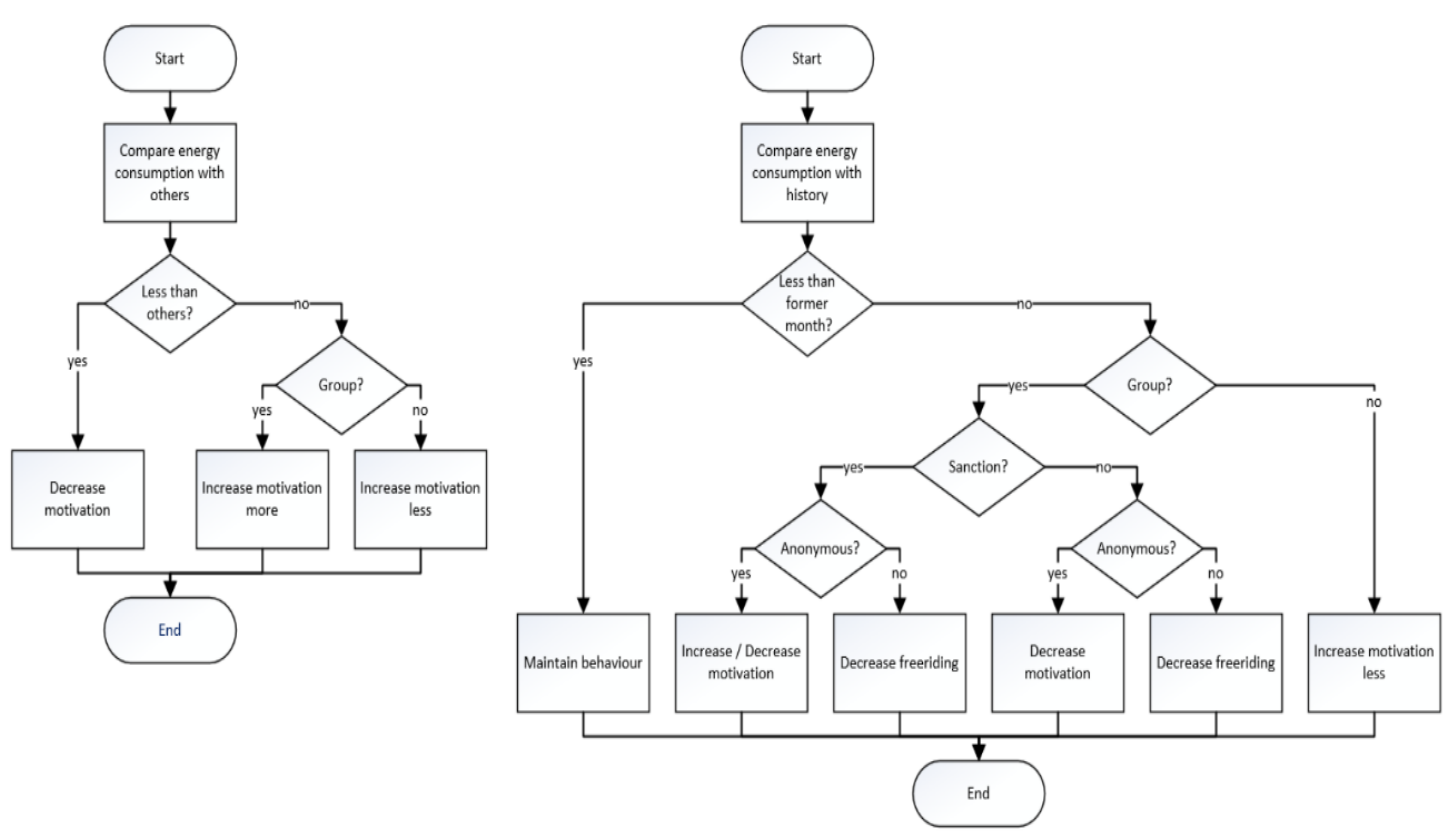

Figure 2. New Algorithm Flowchart

Table 4. The New Algorithm Rationale

\begin{tabular}{ll}
\hline No. & Rationale \\
\hline 1. Having knowledge of other people's behaviours works as 'descriptive norms' to the group, and people will be inclined to \\
follow these norms and act similarly [9], [10], [11]. \\
- Energy feedback often focuses on individual actions and related small costs/savings, which may dishearten individuals \\
given that they see their actions only having a relatively minor impact [8]. Observing the larger scale consumption \\
apportioned to a group may increase perceived instrumentality, a significant factor in promoting energy-saving behaviour \\
[12], [13]. \\
With regard to descriptive norms, if in fact it is observed that others tend to consume more, then people may actually increase \\
their usage as a result [14], [15]. \\
Freeriding tends to be more common in larger groups and when individual behaviour is more anonymous [16]. \\
Making mechanisms available to identify free-riders [17] and implementing sanctions (social, e.g. gossip, or institutional, e.g. \\
fines) to prevent further freeriding [18]. \\
The injustice of freeriding encourages anger and confrontation [19], and there is potential for unjustified scapegoating when \\
there is no specific evidence of individual consumption. \\
- There are some evidences that not revealing exactly who has consumed what proportion of a resource may result in \\
increased fear or guilt and lead to reduced consumption overall through compensating behaviour [20], [5]. \\
However, the impact of this was found to be minor, and deliberate attempts to instil uncertainty may clash with more \\
traditional organisational values of teamwork.
\end{tabular}




\section{EXPERIMENTATION}

\subsection{Experimental Design}

Although office is closed overnight, there are some electrical appliances that still consume energy. For example, when users leave the computer on when they leave the office. So, this model is a nonterminating simulation and the output of non-terminating system often reach a steady state. The simulation output is stochastic because it depends on user behaviour which is determined by any random event.

\subsubsection{Warm up Periode}

The model compares monthly energy consumption. However, at the start of the simulation run it might not the beginning of the month. It might lead to much lower energy consumption which is not realistic. The inclusion of such data would bias the results obtained from the simulation. Graphical method that visually inspects time-series output data was used to identify initialization bias and determine the warm-up period. Because data can be very noisy and make it difficult to spot initialization bias, at least five replications should be performed [6]. Mean averages of those replications for each month is presented in the Figure 3 and warm-up period is the point at which the output appears to settle into a steady state. From the graph in Figure 3, warm-up period for this experiment is 4, which means total energy consumption in the first month until the fourth month will be omitted in the analysis.

\subsubsection{Number of Replication}

To obtain sufficient output data, the result from a single replication is not reliable. A graphical method and confidence interval method were used to determine the number of replication. Graphical method was performed by plotting cumulative mean of the output data from a series of replications. The number of replications required was defined by the point at which the line becomes flat.

Confidence interval is used to show how accurately the mean average of a value is being estimated by using a statistical mean. The narrower the interval the more accurate the estimate it deemed to be. Confidence interval 95\% with significance level 5\% was chosen for this model. It means that $95 \%$ probability that the value of the true mean (obtained if the model is run for an infinite period) lies within the confidence interval. The estimated number of replication for this model is 5 .

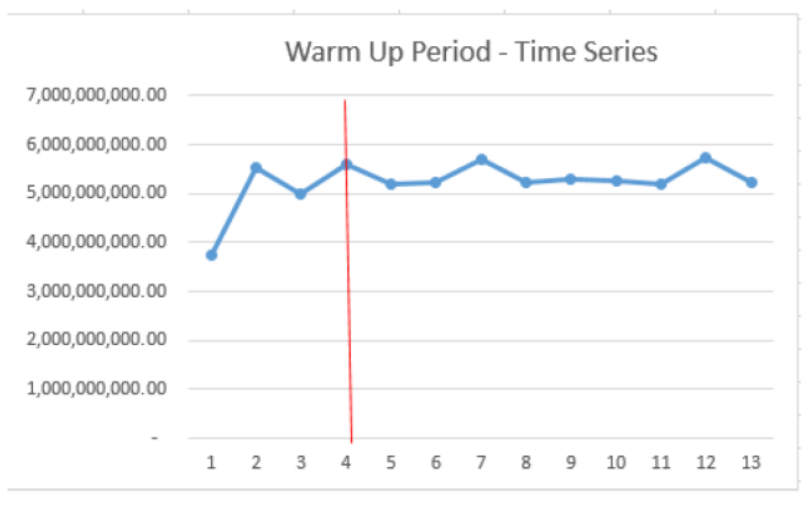

Figure 3. Warm Up Period Graph

Table 5. Experimentation Result

\begin{tabular}{crcl}
\hline \multirow{2}{*}{ Replication } & \multicolumn{3}{c}{ Average Monthly Energy Consumption } \\
& No Apportionment & Individual Apportionment & Group Apportionment \\
\hline 1 & $1,013,363.80$ & $917,511.81(-9.46 \%)$ & $825,872.78(-18.50 \%)$ \\
2 & $947,377.38$ & $938,763.43(-0.91 \%)$ & $887,671.28(-6.30 \%)$ \\
3 & $1,036,726.87$ & $937,589.35(-9.56 \%)$ & $866,805.62(-16.39 \%)$ \\
4 & $1,108,863.01$ & $968,278.02(12.68 \%)$ & $915,456.87(-17.44 \%)$ \\
5 & $1,097,287.42$ & $938,288.99(-14.49 \%)$ & $902,786.73(-17.73 \%)$ \\
\hline
\end{tabular}

\subsubsection{Run Length}

Because non-terminating simulation does not have a natural end point, the length of a simulation run needs to be determined by the model user. Run-length was calculated by plotting cumulative means and convergence based in five replications. Although the calculation indicate that the minimum run-length is 6 , 
the run-length for this simulation is 12 months. It is because the simulation result is going to be compared with an energy conservation research result from Cornell University [7].

\subsection{Experimentation}

\subsubsection{Experimental Validation}

The simulation re-implemented and simplified Zhang's model [3]. It only simulated combine energy management strategy where user can manually switch off the light but in case user do not switch it off, light will automatically switch off after the office is empty for 20 minutes. Without implementation of any intervention strategy and using same input value (same working time, user energy awareness level, total number of user that occupy office building also same total number of lights and computer that is installed in the building), hourly energy consumption between [3] and this model is relatively the same.

The experiment result from individual apportionment was compared with the average energy reduction from [7] about using comparative feedback to influence workplace energy conservation with case study in Cornell University [7] to check the validity of the experiment result.

The experimentation result, shown in Table 5, gives higher reduction percentage compared to [7], in the range of $0.91 \%$ to $18.50 \%$ and constantly reducing the energy consumption. These differences might be caused of the simplification of real world in Table 1. First, in the real world reducing energy consumption month-on-month might not always feasible. The best individual or group might not be able to reduce their consumption anymore. Second, each person has different motive and goal. People with achievement oriented will be more motivated when comparative feedback on energy usage is presented to them, since they care about performance and personal loss/gain, rather than people with altruistic value. Altruistic also more likely to be demotivated by sanction or free-riding. Last, this simulation only focuses on light and computer (in the real-world HVAC consume most of energy in non-residential building [21]) while [7] considers all electricity consumption in the building. Furthermore, the simulation shows that without any intervention the total energy consumption is considerably stable while [7] shows that there are two buildings that slightly reduce their energy consumption even though they were not participating in the campaign. It might be because there are higher number of staff that have altruistic value in those building which is not reflected in this simulation.

\subsubsection{Sensitivity Analysis}

The presence of estimated data in a simulation leaves some uncertainty about the validity of the model and would no doubt reduce its credibility. One way to overcome this issue is performing sensitivity analysis to get insight about the subject of interest.

First, the motivation level as an input is varied for both scenario. One that simulate all staff has very low motivation level (0) and another one simulates all staff has very high motivation level (98). The effect on the total energy consumption in a year, Figure 4(a), shows a steep gradient which means there is a significant shift in the response. It can be concluded that the response is sensitive to the change in the input.

In apportionment strategy to group level, sanction and ability to identify individual consumption in group also give impact to motivation level. Sensitivity analysis result for sanction and anonymity factor in Figure 4(b) shows that both factors do not have a significant impact toward total energy consumption.

\subsubsection{Scenario}

The model consists of 4 office rooms, 1 corridor, and 1 public area, 27 lights installed, and occupied by 24 people who have their own computer in their own office. 5 replications were executed for each scenario.

Each user will be assigned a work time stereotype and energy saving awareness stereotype using a random probability. Their energy saving awareness stereotype determines the motivation level and motivation level determines user behaviour in using unnecessary electrical appliances. If their motivation level is higher than threshold value, more likely user will switch off appliances when they are no longer use it. Otherwise, the appliances will either automatically switch off or enter standby state after a certain period to conserve energy.

In order to compare the impact between individual and group apportionment, two different scenarios will be run during experimental stage;

a. Scenario 1: Apportioned to Individual level, Anonymous, Informative Feedback available, sanction implemented

b. Scenario 2: Apportioned to Group, Anonymous, Informative Feedback available, sanction implemented

Total energy consumption of the whole office that is produced monthly will be analysed to see how different approaches is affect the outcome. 

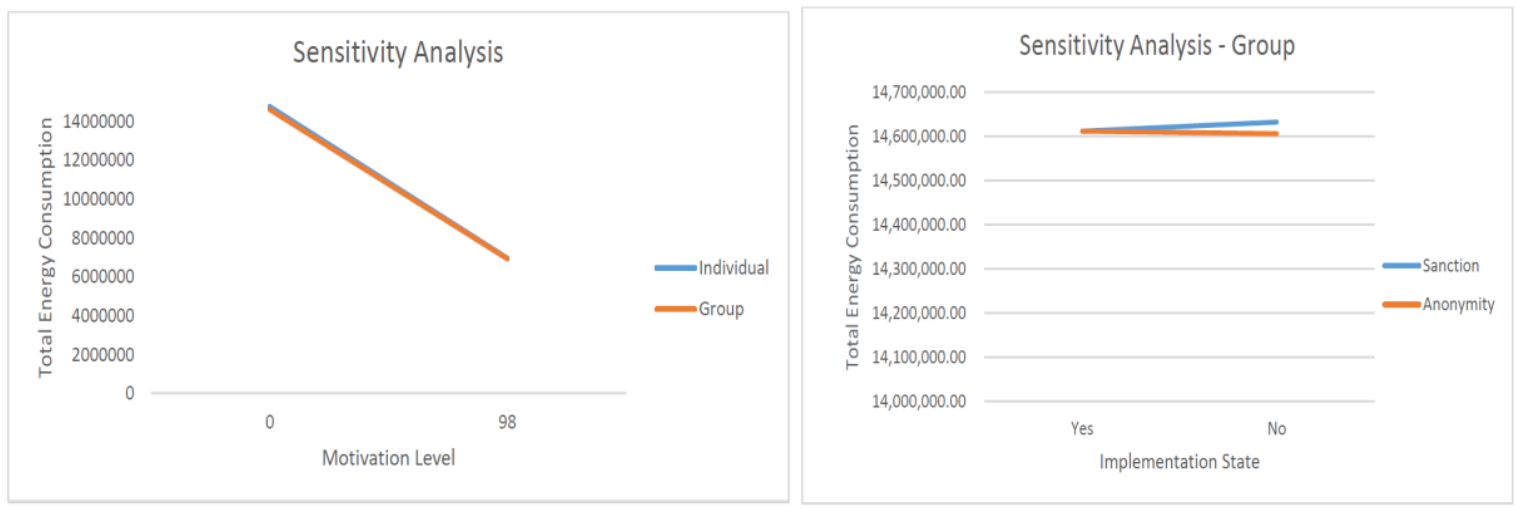

Figure 4. (a) Motivation Level (b) Sanction and Anonimity in Group impact toward Total Energy

Consumption

\subsubsection{Ouput Comparison from Scenarios}

The experiment result as shown in Figure 5 shows that without intervention the total energy consumption is relatively stable for along the year while presenting energy usage feedback to staff in the building reduce the total energy consumption. The total energy consumption reduction between apportionment strategy to individual level and group level shows a similar pattern. However, the total energy consumption of group apportionment slightly reduces more energy consumption than individual apportionment. Because visual comparison between individual and group consumption only shows insignificant difference, further analysis using statistic method need to be performed to observe whether the difference is statistically significant.

As explained in [5], although underlying group goals on collective consumption provides the opportunity for individuals to freeride, aggregate amount presented in group apportionment which give higher or more significant saving is highly motivating compared to small saving on individual action which may dishearten individuals given that they see their actions only having a relatively minor impact [8].

Nonetheless, it must note that in Section 2.1 it is assumed that the potential free-rider is constantly $10 \%$ of the total group member while in the real world very large groups may encourage more free-riding because an individual may believe that it is easier to hide. Moreover, in the context of energy monitoring the optimum group size is yet unknown.

\subsubsection{Energy Comparison based on user's awareness}

Total energy consumption per energy awareness as shown in Figure 6 shows that the energy consumed by Big User and General User is almost the same while Energy Saver and Environmental Champion only consume almost half of Big and General User consumption.

Since there is only slight difference of energy consumption between Energy Saver and Environmental Champion stereotype, it is not necessary to change staff behaviour to become an Environmental Champion. They are expected to maintain their level of consumption. Changing user behaviour from Big User or General User to Energy Saver can save the organisation a lot of money.

\subsubsection{Number of Staff per Stereotype per month}

Comparative feedback on energy usage influence user's motivation level. Since users are categorized to a certain stereotype based on motivation level, the changes of motivation level will change user's stereotype. Figure 7 shows that using group apportionment strategy the changes in the total number of staff per stereotype is faster. Staff starts to shift to a better stereotype around the third month. The shift significantly occurs around the eighth month.

\section{RESULT ANALYSIS}

Beside compare the graph visually, deeper analysis using paired-t confident interval comparison was performed. This method identifies the statistical significance of a difference in the result from two scenarios. It looks at the mean value of each case, standard deviation and number of replication. Paired-t confidence interval comparison is calculated using formula defined in [6]. 


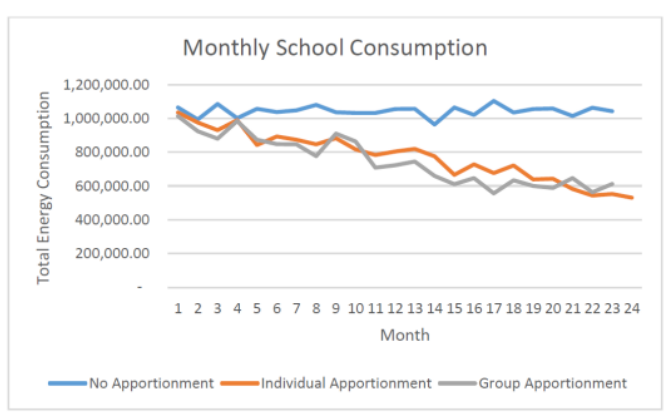

Figure 5. Energy Consumption for Each Apportionment

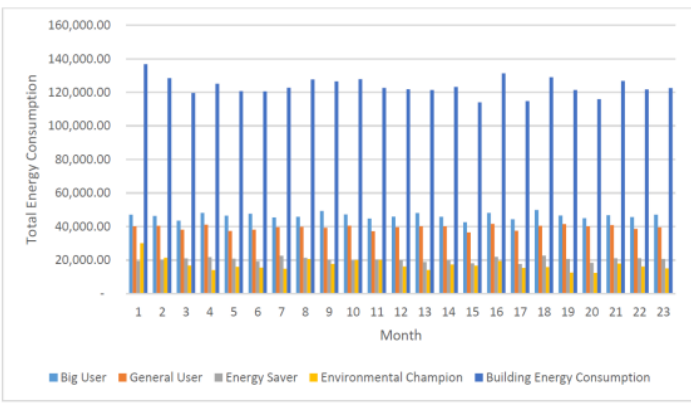

Figure 6. Total Energy Consumption per Stereotype

Five replications were performed for each scenario, then the average monthly energy consumption within a year is used for this analysis. The calculation result is shown in Table 6. Since the confidence interval is a to the right of zero, it can be concluded with specified level of confidence (95\%) that the result of Scenario 1 is greater than the result of Scenario 2. However, because the aim is to reduce energy consumption, Scenario 2 is to be preferred.
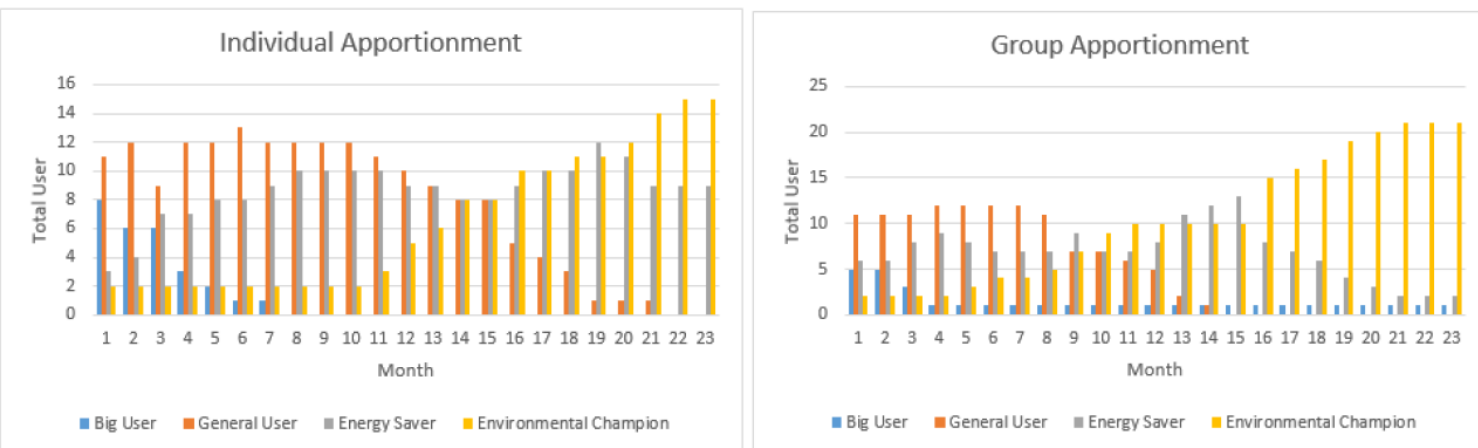

Figure 7. The Changes in the total number of staff per stereotype

Table 6. Paired-t Confidence Interval Comparison Calculation

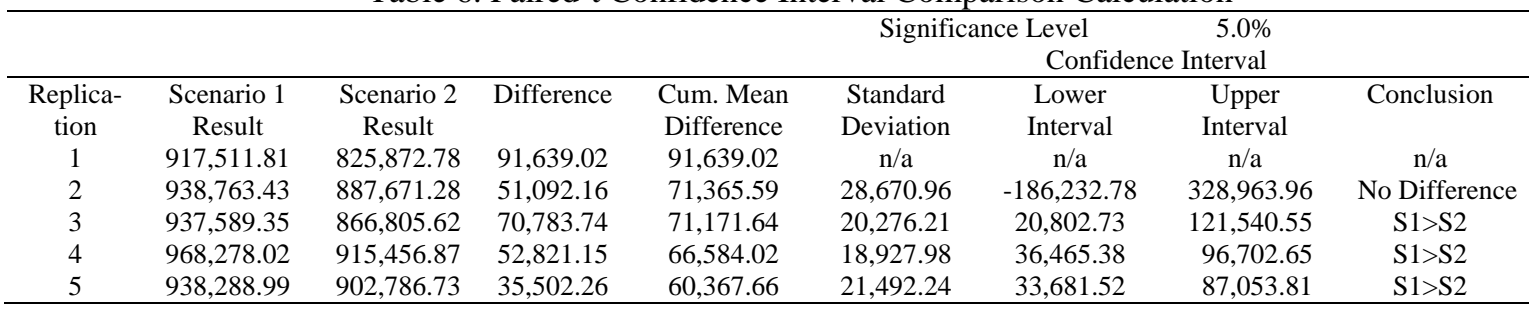

\section{CONCLUSION}

Since collecting fine-grained energy data in workplace is increasingly possible and changing user behaviour using comparative feedback strategy provides a potential to reduce energy consumption, this research is aimed to understand the impact of applying different approaches of energy data apportionment to change staff behaviour toward energy consumption reduction by re-implementing and extending the former model, add several psychological factors into the model.

The new algorithm reflects psychological factor when comparative feedback campaign is used as an intervention strategy to change energy behaviour in workplace. From the experimentation result it can be concluded that motivation plays an important role in changing user behaviour while sanction and ability to identify individual consumption in group does not. Big and General User are the target of behaviour change strategy because changing their behaviour has significant impact in lowering whole energy usage thus help 
the organisation saves money. Moreover, apportionment strategy to group level give higher result in energy consumption reduction for the whole building even though it provides opportunity for individual to freeride. The conclusion only accurately reflects lights and computer consumption. In the model scope there are some items that were identified to have significant impact toward energy consumption and energy conservation but does not included in this research.

\section{REFERENCES}

[1] Nolan, J., Schultz, P., Cialdini, R., Goldstein, N., \& Griskevicius, V. "Normative Social Influence is Underdetected". Personality and Social Psychology Bulletin, 2008; 34(7): 913-923

[2] Carrico, A. R., \& Riemer, M. "Motivating energy conservation in the workplace: An evaluation of the use of grouplevel feedback and peer education”. Journal of Environmental Psychology, 2011; 31: 1-13. doi:10.1016/j.jenvp.2010.11.004

[3] T. Zhang, et al., "Modelling electricity consumption in office buildings: An agent-based approach". Energy Buildings. 2011 doi:10.1016/j.enbuild.2011.07.007

[4] Webster, John. 'Europe Is Missing Out On A Huge Climate Opportunity - And €2.4Billion A Year In Energy Savings'. The Huffington Post UK. N.p., 2015. Web. 20 July 2015. http://www.huffingtonpost.co.uk/johnwebster/europe-is-missing-out-on-_b_5529827.html

[5] Ben Bedwell, Caroline Leygue, Murray Goulden, Derek McAuley, James Colley, Eamonn Ferguson, Nick Banks \& Alexa Spence. "Apportioning energy consumption in the workplace: a review of issues in using metering data to motivate staff to save energy", Technology Analysis \& Strategic Management. 2014; 26:10, 1196-1211, DOI: 10.1080/09537325.2014.978276

[6] Robinson, S. "Simulation: The Practice of Model Development and Use". Chichester, Eng.: Wiley. 2004.

[7] Dixon, G. N., Deline, M. B., McComas, K., Chambliss, L., \& Hoffmann, M. "Using comparative feedback to influence workplace energy conservation: A case study of a university campaign”. Environment and Behavior, 2015; 47(6): 667-693.

[8] Spence, A., C. Leygue, B. Bedwell, and C. O'Malley. "Engaging with Energy Reduction: Does a Climate Change Frame have the Potential for Achieving Broader Sustainable Behaviour?" Journal of Environmental Psychology. 2014; 38: 17-28.

[9] Cialdini, R. B., C. A. Kallgren, and R. R. Reno. "A Focus Theory of Normative Conduct: A Theoretical Refinement and Reevaluation of the Role of Norms in Human Behaviour." In Advances in Experimental Social Psychology, 1991; 201-234. New York, NY: Academic.

[10] Cialdini, R. B. "Crafting Normative Messages to Protect the Environment." Current Directions in Psychological Science. 2003; 12 (4): 105-109.

[11] Thogersen, J. "Norms for Environmentally Responsible Behaviour: An Extended Taxonomy." Journal of Environmental Psychology. 2006; 26 (4): 247-261.

[12] Locke, E. A., and G. P. Latham. "Building a Practically Useful Theory of Goal Setting and Task Motivation: A 35year Odyssey." American Psychologist. 2002; 57: 705-717.

[13] Spence, A., W. Poortinga, C. Butler, and N. Pidgeon. "Perceptions of Climate Change and Willingness to Save Energy Related to Flood Experience." Nature Climate Change, 2011; 1: 46-49.

[14] Brandon, G., and A. Lewis. "Reducing Household Energy Consumption: A Qualitative and Quantitative Field Study." Journal of Environmental Psychology. 1999; 19 (1): 75-85.

[15] Fischer, C. "Feedback on Household Electricity Consumption: a Tool for Saving Energy?" Energy Efficiency. 2008 1 (1): 79-104.

[16] Hamburger, H., M. Guyer, and J. Fox. “Group Size and Cooperation.” The Journal of Conflict Resolution. $1975 ; 19$ (3): 503-531.

[17] Haley, K. J., and D. M. T. Fessler. "Nobody's Watching? Subtle Cues Affect Generosity in an Anonymous Economic Game." Evolution and Human Behavior. 2005; 26 (3): 245-256.

[18] Fehr, E., U. Fischbacher, and S. Gächter. "Strong Reciprocity, Human Cooperation and the Enforcement of Social Norms." Human Nature. 2002; 13: 1-25.

[19] Carver, C. S., and E. Harmon-Jones. "Anger is an Approach-related Affect: Evidence and Implications." Psychological Bulletin. 2009; 135 (2): 183-204.

[20] Elgaaied, L. "Exploring the Role of Anticipated Guilt on Pro-environmental Behavior - A Suggested Typology of Residents in France Based on their Recycling Patterns." Journal of Consumer Marketing. 2012; 29 (5): 369-377.

[21] US Energy Information Administration (EIA) Commercial Buildings Energy Consumption Survey (CBECS), 2003

\section{BIOGRAPHY OF AUTHOR}

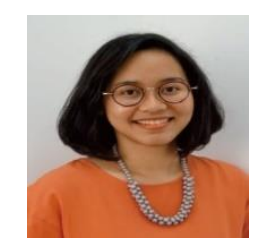

Meredita Susanty received master's degree in Management of Information Technology from University of Nottingham in 2015. She is currently working at Department of Computer Science, University Pertamina. 